\title{
Synthesis and Characterization of Boehmite Nanofibers
}

\author{
Jing Yang and Ray L. Frost \\ Inorganic Materials Research Program, School of Physical and Chemical Sciences, Queensland University of Technology, \\ GPO Box 2434, Brisbane, Qld 4001, Australia
}

Correspondence should be addressed to Ray L. Frost, r.frost@qut.edu.au

Received 18 June 2008; Accepted 5 August 2008

Recommended by Yining Huang

Boehmite nanofibers of high quality were synthesized through a wet-gel conversion process without the use of a surfactant. The long nanofibers of boehmite with clear-cut edges were obtained by steaming the wet-gel precipitate at $170^{\circ} \mathrm{C}$ for 2 days. Analytical techniques such as X-ray diffraction (XRD), scanning electron microscopy (SEM), infrared emission spectroscopy (IES), as well as Raman spectroscopy were used to characterize the products.

Copyright (C) 2008 J. Yang and R. L. Frost. This is an open access article distributed under the Creative Commons Attribution License, which permits unrestricted use, distribution, and reproduction in any medium, provided the original work is properly cited.

\section{Introduction}

The $\gamma$ - and $\alpha-\mathrm{Al}_{2} \mathrm{O}_{3}$ polymorphs have found numerous applications in technical ceramics, thin solid films, catalysis, and many others. In many cases, boehmite $\gamma-\mathrm{AlO}(\mathrm{OH})$ is the starting material in the applications of alumina phases. As a typical oxyhydroxy compound, boehmite is also extensively used as an absorbent $[1,2]$, a catalyst [3], and an optical material [4]. Nanosized materials are well known for their quantum size effects [5] and are expected to gain novel physical and chemical properties, with many more potential applications in a wide range of areas. In recent years, boehmite with nanoscale dimensions and morphological specificity has attracted enormous interest from both fundamental and practical viewpoints.

Boehmite nanofibers were reported to be assembled with the assistance of poly(ethylene oxide) (PEO) surfactant [6], and tubular $\gamma-\mathrm{Al}_{2} \mathrm{O}_{3}$ was fabricated via soft solution route using $\mathrm{N}$-cetyl- $\mathrm{N}, \mathrm{N}, \mathrm{N}$-trimethylammonium bromide surfactant [7]. A solution-based chemical synthesis of boehmite nanofibers and alumina nanorods by a modified sol-gel process in the presence of organic solvents has been reported [8]. Shen et al. reported a steam-assisted solid-phase conversion of amorphous aluminium hydroxide wet gel to well-crystallized 1D nanostructured boehmite nanorods without using surfactants and organic solvents [9]. The process is unique in the simplicity of preparation and the high efficiency of crystal growth, which can be operated on a large scale.

In this work, long, large boehmite nano/microfibers with high crystallinity and purity were synthesized based on Shen's methodology [9], and the characterization of these nano/microfibers is reported.

\section{Experimental}

2.1. Preparation Procedures. $15 \mathrm{~g}$ of $\mathrm{Al}\left(\mathrm{NO}_{3}\right)_{3} \cdot 9 \mathrm{H}_{2} \mathrm{O}$ was dissolved in $25 \mathrm{~mL}$ ultrapure water, and $28 \%$ ammonia aqueous solution was diluted into $10 \%$ solution. At room temperature, $10 \%$ ammonia solution was added dropwise into $\mathrm{Al}\left(\mathrm{NO}_{3}\right)_{3}$ solution at a constant rate of $5 \mathrm{~mL} / \mathrm{min}$ while stirring vigorously. Ammonia was ceased to be added when the $\mathrm{pH}$ value of the reaction mixture reached 5 . The reaction mixture was stirred constantly in air at room temperature for 1 hour. The obtained white gel was filtered to obtain the wet gel-cake, which was then transferred into a glass beaker $(25 \mathrm{~mL})$. Before transferring the beaker with wet gelcake into a Teflon vessel $(125 \mathrm{~mL}), 2 \mathrm{~mL}$ ultrapure water was added into the bottom of the vessel. The Teflon vessel was sealed and heated at $170^{\circ} \mathrm{C}$ for 2 days. The resulting white material was washed with ultrapure water, centrifuged and dried at $35^{\circ} \mathrm{C}$ for 2 days. 


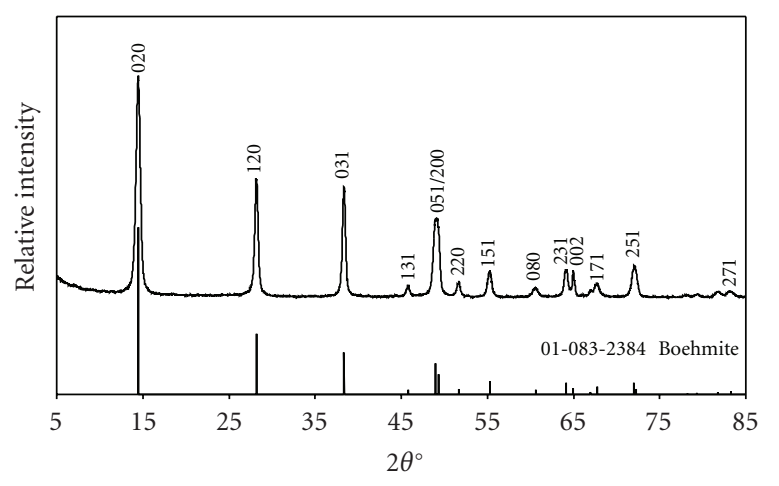

FIGURE 1: XRD pattern of the synthetic boehmite nanofibers, after hydrothermal treatment at $170^{\circ} \mathrm{C}$ for 2 days.

2.2. Characterization. X-ray diffraction analyses were performed on a PANalytical X'Pert PRO X-ray diffractometer, with a $\mathrm{Cu} X$-ray tube $(\lambda=1.540596 \AA)$, operating at $40 \mathrm{kV}$ and $40 \mathrm{~mA}$. The scanning electron microscopy (SEM) images were taken with a FEI Quanta 200 operating at $25 \mathrm{kV}$. The specimens were mounted on SEM mounts with carbon tape and sputter-coated with a thin layer of gold. The infrared emission spectroscopy was carried out on a Nicolet Nexus 870 FTIR spectrometer. The emission spectra were collected at an interval of $50^{\circ} \mathrm{C}$, over the range $100^{\circ} \mathrm{C}-850^{\circ} \mathrm{C}$. Further details have been published [10-13]. Raman spectra were obtained using a Renishaw 1000 Raman microscope system, which also includes a monochromator, a filter system, and a charge-coupled device (CCD). 64 Raman spectra were collected using $5 \mathrm{~mW}$ of power at the sample using 20-second scans. Further details of the Raman technique have been published [14-19].

\section{Results and Discussion}

3.1. X-Ray Diffraction. X-ray diffraction is normally used to determine the phase and phase purity of the synthesized boehmite. Figure 1 displays well-defined XRD pattern observed, and all diffraction peaks were perfectly indexed to the XRD pattern of pure boehmite (JCPDS card 01-0832384). No XRD peaks representing other crystalline phases were detected, indicating that the nanofibers of the synthetic boehmite exhibited excellent crystallinity and a high purity.

3.2. Scanning Electron Microscopy. While TEM images are normally used to show the morphology of the boehmite nanomaterials, if the nanofibres are large enough in length, then scanning electron microscopy can be used to prove the nature of the nano/micromaterial. Figure 2 presents the SEM image of the synthetic boehmite nanofibers. Nanofibers up to $500 \mathrm{~nm}$ long in bundles are clearly seen. Zhu et al. [20] reported that through a soft-templated process with PEO surfactant micelles at $100^{\circ} \mathrm{C}$, the nanofibers could be assembled, the maximum length of which was $100 \mathrm{~nm}$. In this study, the nanofibers were synthesized in the absence of surfactant and in a supersaturated hydrothermal condition, which was reported by Shen et al. [9]. This steam-assisted

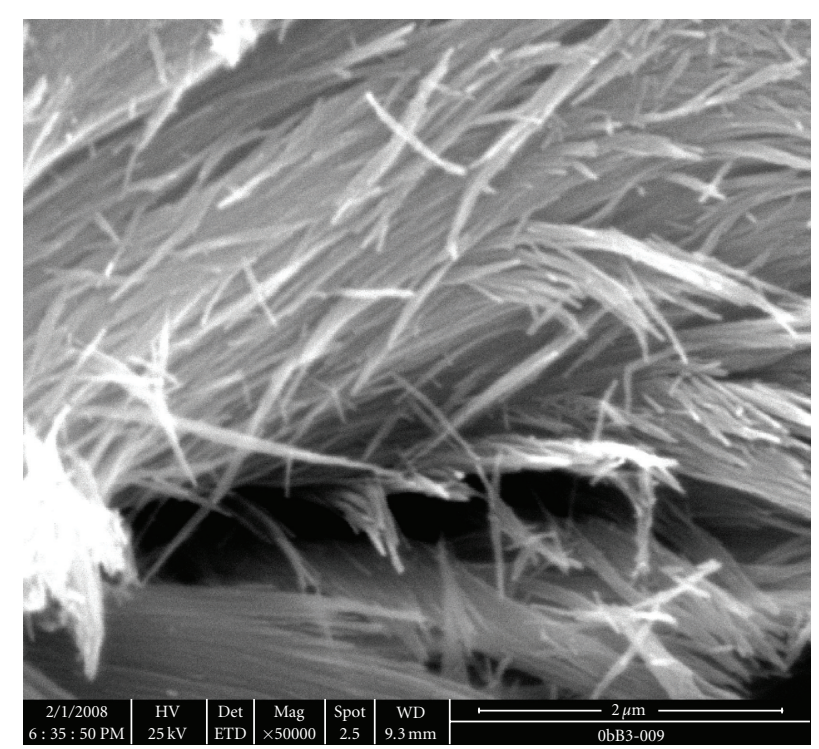

Figure 2: SEM image of the synthetic boehmite nanofibers, after hydrothermal treatment at $170^{\circ} \mathrm{C}$ for 2 days.

self-assembly fabrication of boehmite yielded high-quality 1D nanostructures with clear-cut edges and high purity. The structure was confirmed by the XRD patterns.

3.3. Infrared Emission Spectroscopy. Infrared emission spectroscopy (IES) is known as a measurement of discrete vibrational frequencies emitted by thermally excited molecules. The major advantages of IES are that the samples are measured in situ at the elevated temperature and IES requires no sample treatment other than making the sample of submicron particle size. Figure 3 clearly shows such a suite of the dehydroxylation of the synthetic boehmite nanofibers. The dehydroxylation is followed by the decrease of intensity of the hydroxyl deformation modes and the loss of intensity of the hydroxyl stretching frequencies. The hydroxyl deformation frequencies are observed at $840 \mathrm{~cm}^{-1}$ and $757 \mathrm{~cm}^{-1}$. The spectral changes in these low-frequency bands show that dehydroxylation commenced at $250^{\circ} \mathrm{C}$. The three bands displayed at $3671 \mathrm{~cm}^{-1}, 3360 \mathrm{~cm}^{-1}$, and $3140 \mathrm{~cm}^{-1}$ are recognized in the hydroxyl stretching region. Above $450^{\circ} \mathrm{C}$, the hydroxyl stretching bands are no longer observed. These spectral changes confirm that dehydroxylation starts at $250^{\circ} \mathrm{C}$ and is completed by $450^{\circ} \mathrm{C}$. Each of the hydroxyl stretching bands shows an increase in bandwidth with temperature increase, and this indicates that the molecular structure of the boehmite nanofibers was becoming more disordered during the dehydroxylation process.

3.4. Raman Spectroscopy. Many minerals, both natural and synthetic, lend themselves to analysis by Raman spectroscopy. The great advantage of Raman spectroscopy is that just so long as the materials are 1 micron in size or larger, then individual nanofibres can be analysed as is the case for the boehmite fibres shown above. 


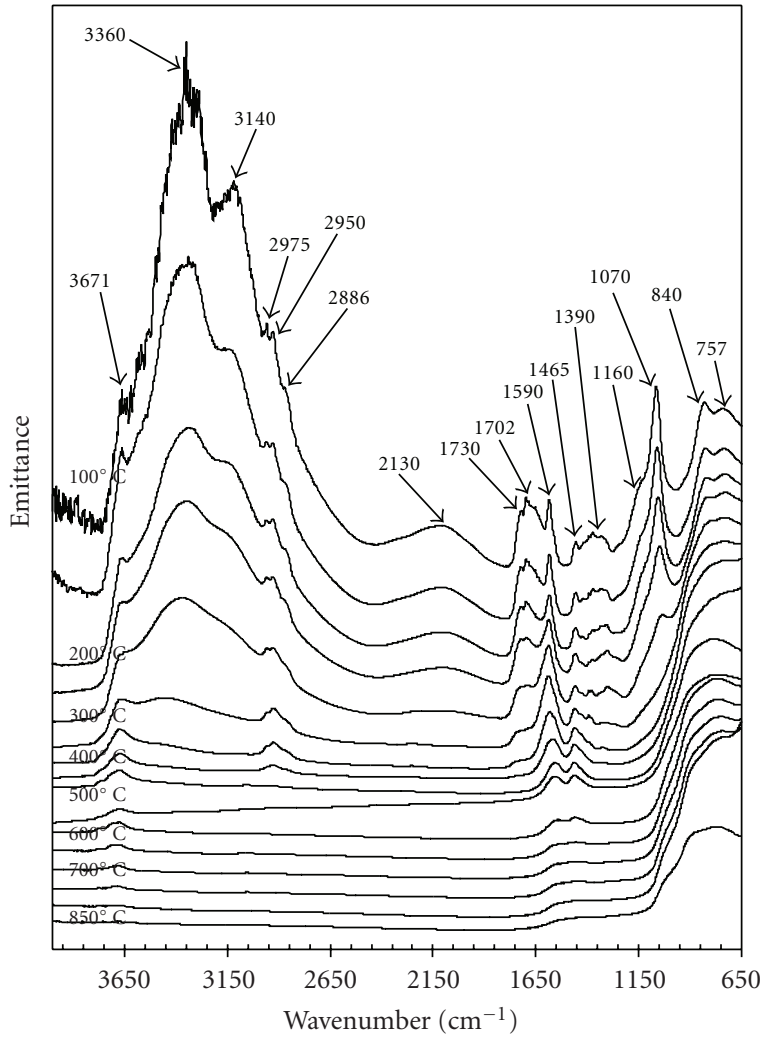

FIGURE 3: IES spectra of the synthetic boehmite nanofibers, collected at an interval of $50^{\circ} \mathrm{C}$, over the range $100^{\circ} \mathrm{C}-850^{\circ} \mathrm{C}$.

Figure 4 depicts the Raman spectra of the synthetic boehmite nanofibers. The bands at 3216, 3077, and $2989 \mathrm{~cm}^{-1}$ are in the region of the hydroxyl stretching vibrations. Frost et al. [21] characterized hydroxyl stretching bands in the Raman spectrum of boehmite and reported bands at 3413, 3283, 3096, and $2997 \mathrm{~cm}^{-1}$. The lowwavenumber region $\left(1100-200 \mathrm{~cm}^{-1}\right)$ of boehmite consists of hydroxyl deformation modes $\left(1050-900 \mathrm{~cm}^{-1}\right)$ and hydroxyl translation modes $\left(800-400 \mathrm{~cm}^{-1}\right)$. The doubly degenerate mode of the $\mathrm{AlO}_{6}$ octahedron caused the observation of the bands at 495 and $675 \mathrm{~cm}^{-1}$ [22]. The band at $362 \mathrm{~cm}^{-1}$ was attributed to the vibration of fully symmetric $\mathrm{A}_{g}$ mode, in which all aluminium and oxygen atoms move parallel to the $b$-axis [23]. The weak bands at 732, 448, and $340 \mathrm{~cm}^{-1}$ were attributed to $\mathrm{OH}^{-}$deformation modes [24].

\section{Conclusions}

In this research, long boehmite nanofibers with high crystallinity and purity were formed under steam-assisted hydrothermal treatment at $170^{\circ} \mathrm{C}$ for 48 hours with $\mathrm{pH}$ 5. The structure and morphology of the nanofibers were detected by XRD and SEM, while the IES spectra illustrated their thermal properties. Raman spectroscopy was applied to characterize the 1D nanostructured boehmite.

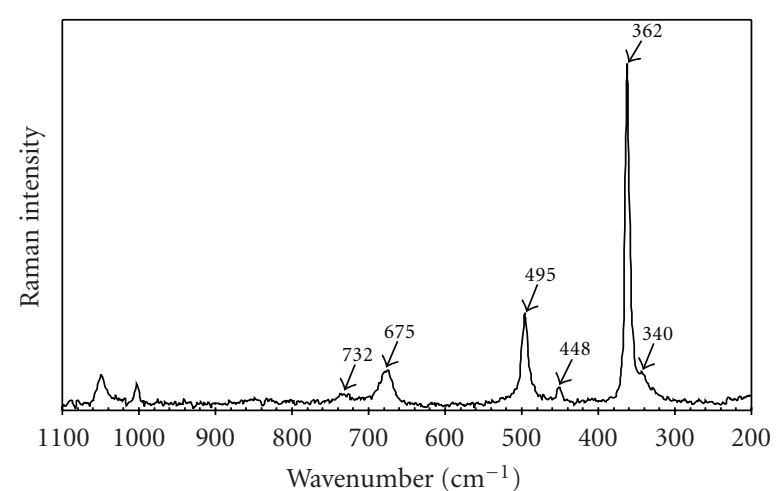

(a)

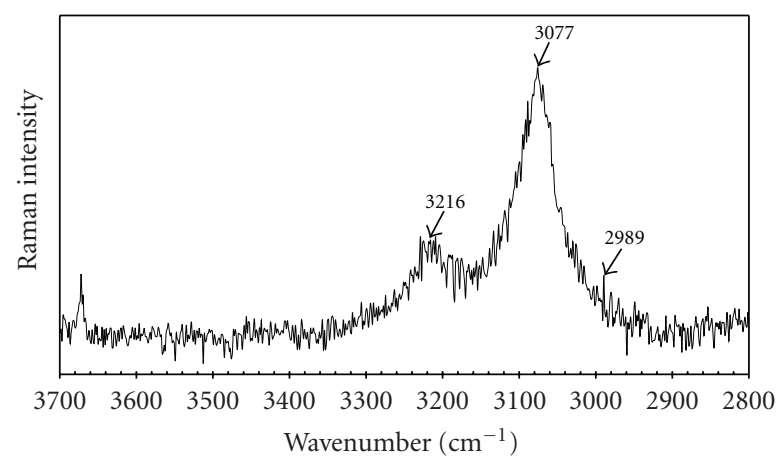

(b)

FIGURE 4: Raman spectra of the synthetic boehmite nanofibers, after hydrothermal treatment at $170^{\circ} \mathrm{C}$ for 2 days.

\section{Acknowledgment}

The financial and infrastructure support of the Inorganic Materials Research Program, School of Physical and Chemical Sciences, Queensland University of Technology, is gratefully acknowledged.

\section{References}

[1] V. S. Burkat, V. S. Dudorova, V. S. Smola, and T. S. Chagina, "Physicochemical properties of alumina used for removing fluorides in the dry cleaning systems," in Light Metals, pp. 1443-1448, TMS, Warrendale, Pa, USA, 1985.

[2] C. Nédez, J.-P. Boitiaux, C. J. Cameron, and B. Didillon, "Optimization of the textural characteristics of an alumina to capture contaminants in natural gas," Langmuir, vol. 12, no. 16, pp. 3927-3931, 1996.

[3] J.-L. Le Loarer, H. Nussbaum, and D. Bortzmeyer, "Alumina extrudates, methods for preparing and use as catalysts or catalyst supports," WO 9856499, December 1998.

[4] D. Mishra, S. Anand, R. K. Panda, and R. P. Das, "Hydrothermal preparation and characterization of boehmites," Materials Letters, vol. 42, no. 1-2, pp. 38-45, 2000.

[5] G. D. Stucky and J. E. Mac Dougall, "Quantum confinement and host/guest chemistry: probing a new dimension," Science, vol. 247, no. 4943, pp. 669-678, 1990.

[6] H. Y. Zhu, X. P. Gao, D. Y. Song, et al., "Growth of boehmite nanofibers by assembling nanoparticles with 
surfactant micelles," The Journal of Physical Chemistry B, vol. 108, no. 14, pp. 4245-4247, 2004.

[7] D. Kuang, Y. Fang, H. Liu, C. Frommen, and D. Fenske, "Fabrication of boehmite $\mathrm{AlOOH}$ and $\gamma-\mathrm{Al}_{2} \mathrm{O}_{3}$ nanotubes via a soft solution route," Journal of Materials Chemistry, vol. 13, no. 4, pp. 660-662, 2003.

[8] S. C. Kuiry, E. Megen, S. D. Patil, S. A. Deshpande, and S. Seal, "Solution-based chemical synthesis of boehmite nanofibers and alumina nanorods," The Journal of Physical Chemistry B, vol. 109, no. 9, pp. 3868-3872, 2005.

[9] S. C. Shen, Q. Chen, P. S. Chow, et al., "Steam-assisted solid wet-gel synthesis of high-quality nanorods of boehmite and alumina," The Journal of Physical Chemistry C, vol. 111, no. 2, pp. 700-707, 2007.

[10] R. L. Frost, G. A. Cash, and J. T. Kloprogge, “'Rocky Mountain leather', sepiolite and attapulgite-an infrared emission spectroscopic study," Vibrational Spectroscopy, vol. 16, no. 2, pp. 173-184, 1998.

[11] R. L. Frost, B. M. Collins, K. Finnie, and A. J. Vassallo, in Clays controlling the environment: Proceedings of the 10th International Clay Conference, pp. 219-224, Adelaide, Australia, July 1993.

[12] R. L. Frost and J. T. Kloprogge, "Infrared emission spectroscopic study of brucite," Spectrochimica Acta Part A, vol. 55, no. 11, pp. 2195-2205, 1999.

[13] R. L. Frost and J. T. Kloprogge, “Tijdschrift voor Klei," Glas en Keramiek, vol. 19, pp. 11-15, 1998.

[14] R. L. Frost and J. Čejka, "A Raman spectroscopic study of the uranyl carbonate rutherfordine," Journal of Raman Spectroscopy, vol. 38, no. 11, pp. 1488-1493, 2007.

[15] R. L. Frost, J. Čejka, G. A. Ayoko, and M. L. Weier, "Raman spectroscopic and SEM analysis of sodium-zippeite," Journal of Raman Spectroscopy, vol. 38, no. 10, pp. 1311-1319, 2007.

[16] R. L. Frost and J. M. Bouzaid, "Raman spectroscopy of dawsonite $\mathrm{NaAl}\left(\mathrm{CO}_{3}\right)(\mathrm{OH})_{2}$," Journal of Raman Spectroscopy, vol. 38, no. 7, pp. 873-879, 2007.

[17] R. L. Frost, M. L. Weier, P. A. Williams, P. Leverett, and J. T. Kloprogge, "Raman spectroscopy of the sampleite group of minerals," Journal of Raman Spectroscopy, vol. 38, no. 5, pp. 574-583, 2007.

[18] R. L. Frost, J. M. Bouzaid, W. N. Martens, and B. J. Reddy, "Raman spectroscopy of the borosilicate mineral ferroaxinite," Journal of Raman Spectroscopy, vol. 38, no. 2, pp. 135-141, 2007.

[19] R. L. Frost, S. J. Palmer, J. M. Bouzaid, and B. J. Reddy, "A Raman spectroscopic study of humite minerals," Journal of Raman Spectroscopy, vol. 38, no. 1, pp. 68-77, 2007.

[20] H. Y. Zhu, J. D. Riches, and J. C. Barry, “ $\gamma$-alumina nanofibers prepared from aluminum hydrate with poly(ethylene oxide) surfactant," Chemistry of Materials, vol. 14, no. 5, pp. 20862093, 2002.

[21] R. L. Frost, J. T. Kloprogge, S. C. Russell, and J. Szetu, "Dehydroxylation of aluminum (oxo)hydroxides using infrared emission spectroscopy—part II: boehmite," Applied Spectroscopy, vol. 53, no. 5, pp. 572-582, 1999.

[22] A. B. Kiss, G. Keresztury, and L. Farkas, "Raman and i.r. spectra and structure of boehmite $(\gamma$-AlOOH). Evidence for the recently discarded $D_{2 h}^{17}$ space group," Spectrochimica Acta Part A, vol. 36, no. 7, pp. 653-658, 1980.

[23] C. J. Doss and R. Zallen, "Raman studies of sol-gel alumina: finite-size effects in nanocrystalline $\mathrm{AlO}(\mathrm{OH})$," Physical Review B, vol. 48, no. 21, pp. 15626-15637, 1993.
[24] T. Assih, A. Ayral, M. Abenoza, and J. Phalippou, "Raman study of alumina gels," Journal of Materials Science, vol. 23, no. 9, pp. 3326-3331, 1988. 


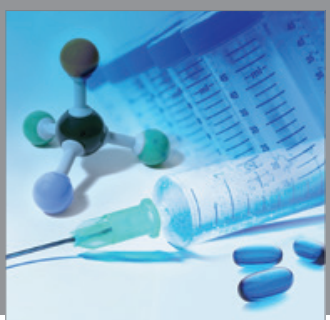

International Journal of

Medicinal Chemistry

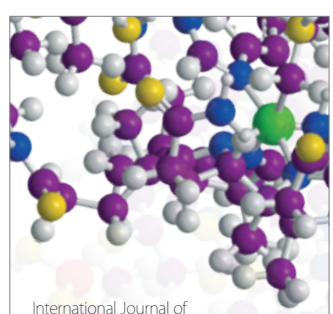

Carbohydrate Chemistry

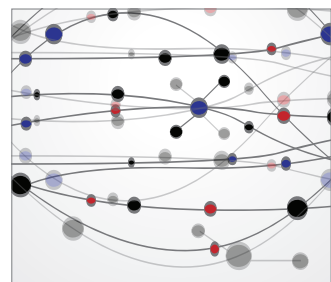

The Scientific World Journal
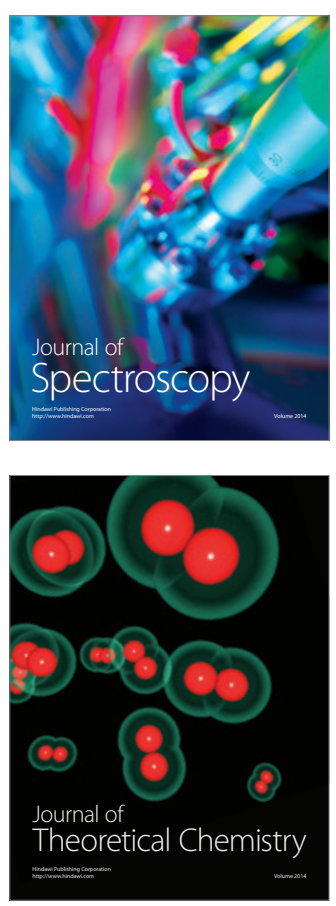
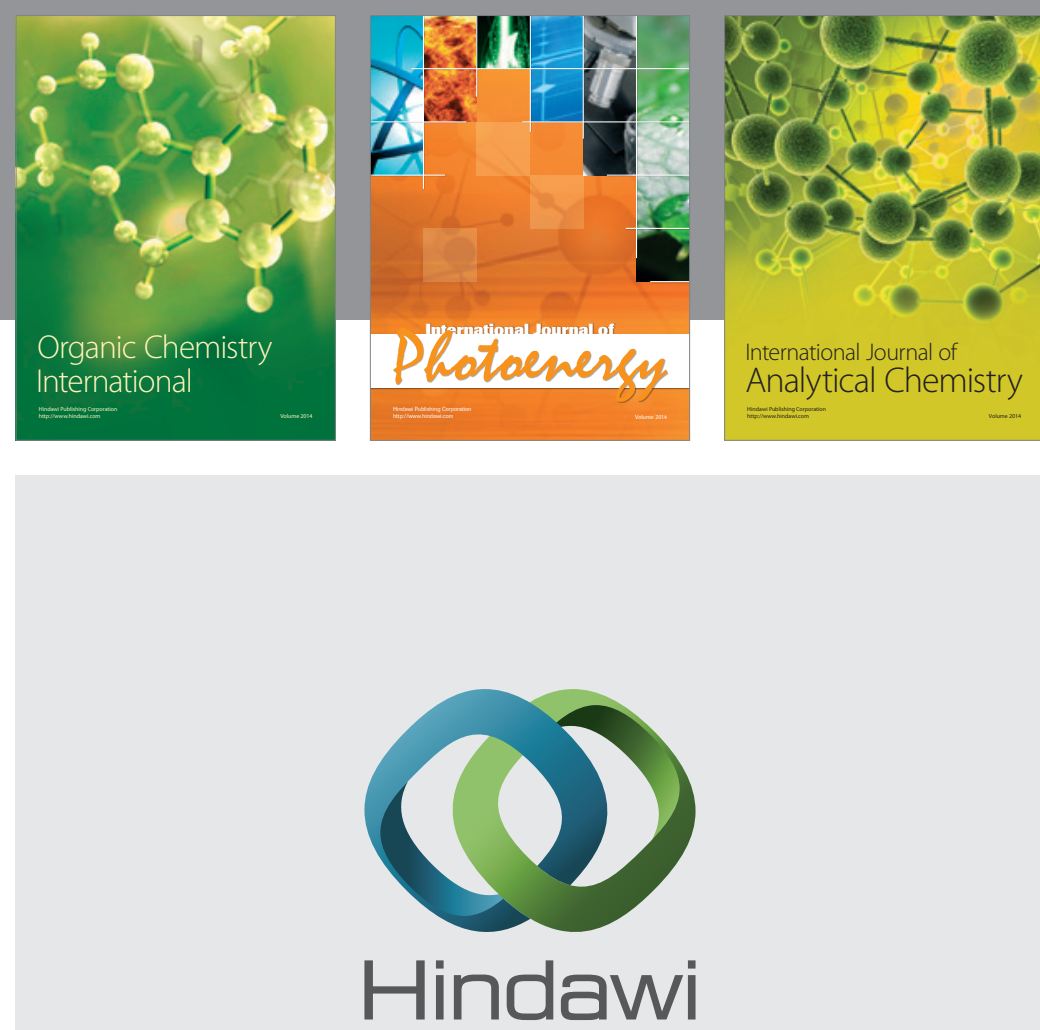

Submit your manuscripts at

http://www.hindawi.com
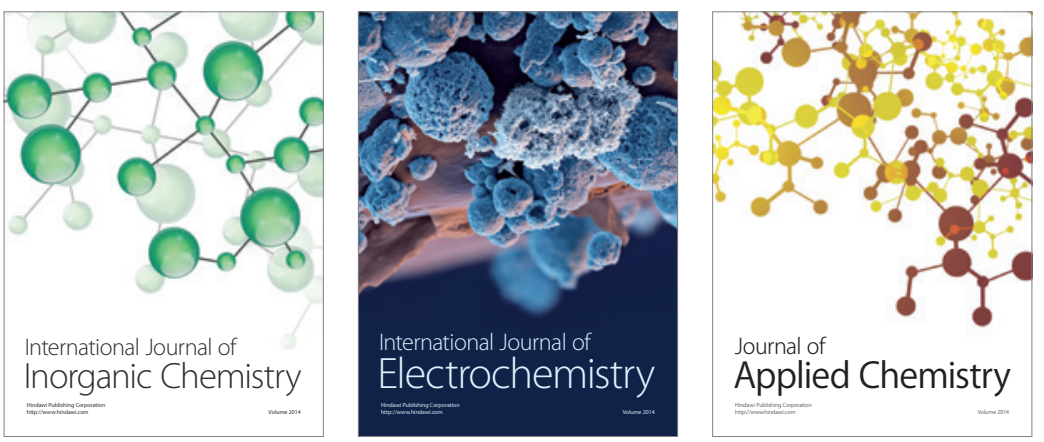

Journal of

Applied Chemistry
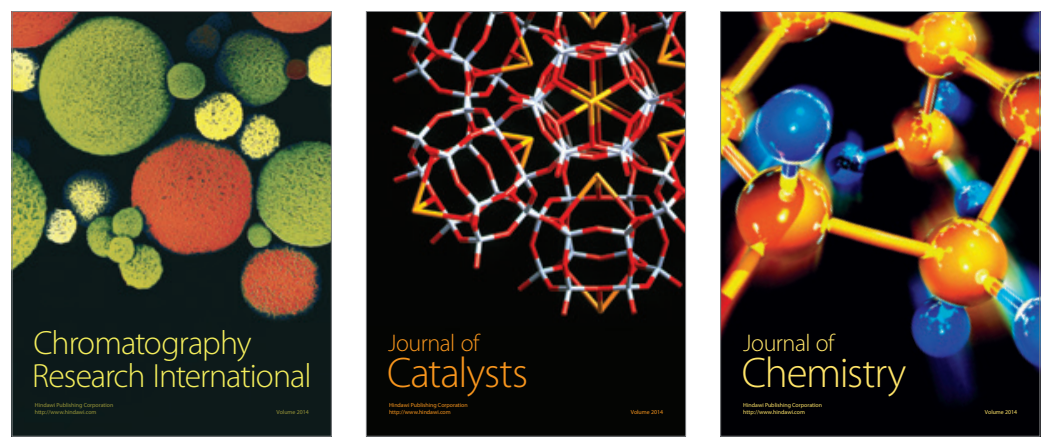
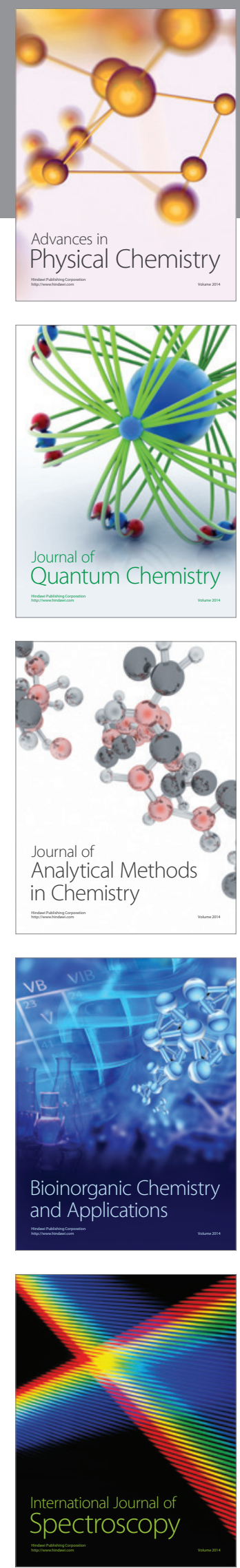